\title{
Correction: Influence of opioid prescribing standards on health outcomes among patients with long-term opioid use: a longitudinal cohort study
}

In an article published Dec. $18,2020,{ }^{1}$ the DOI was incorrectly listed as $10.9778 /$ cmajo.20200228. It should have been 10.9778/cmajo.20190228.

The article has been corrected at cmajopen.ca.

\section{Reference}

1. Morrow RL, Bassett K, Wright JM, et al. Influence of opioid prescribing standards on health outcomes among patients with long-term opioid use: a longitudinal cohort study. CMAF Open 2020;8:E869-E876.

CMAJ Open 2021 October 5. DOI:10.9778/cmajo.20210242 